\title{
Gene expression responses in vivo by human telomerase reverse transcriptase (hTERT)-targeting trans-splicing ribozyme
}

\author{
Min-Sun Song ${ }^{1}$, Jin-Sook Jeong ${ }^{2}$, Kyung-Sook $\mathrm{Cho}^{3}$ \\ and Seong-Wook Lee $e^{1,4}$ \\ ${ }^{1}$ Department of Molecular Biology \\ Institute of Nanosensor and Biotechnology \\ Dankook University \\ Yongin 448-701, Korea \\ ${ }^{2}$ Department of Pathology \\ Medical Center for Cancer Molecular Therapy \\ Dong-A University College of Medicine \\ Busan 602-103, Korea \\ ${ }^{3}$ Research Institute and Hospital \\ National Cancer Center \\ Goyang 411-764, Korea \\ ${ }^{4}$ Corresponding author: Tel, 82-31-8005-3195; \\ Fax, 82-31-8005-4058; E-mail, SWL0208@ dankook.ac.kr
}

Accepted 15 October 2007

Abbreviations: HCC, hepatocellular carcinoma; hTERT, human telomerase reverse transcriptase; PEPCK, phosphoenolpyruvate carboxykinase; PL, Ad-PEPCK-LacZ; PRL, Ad-PEPCK.Ribo-LacZ; TS, trans-splicing

\begin{abstract}
A trans-splicing ribozyme which can specifically reprogram human telomerase reverse transcriptase (hTERT) RNA was previously suggested as a useful agent for tumor-targeted gene therapy. In this study, we evaluated in vivo function of the hTERT-targeting trans-splicing ribozymes by employing the molecular analysis of expression level of genes affected by the ribozyme delivery into peritoneal carcinomatosis mice model. To this effect, we constructed adenoviral vector encoding the specific ribozyme. Noticeably, more than four-fold reduction in the level of hTERT RNA was observed in tumor nodules by the systemic infection of the ribozyme-encoding virus. Such hTERT RNA knockdown in vivo induced changes in the global gene expression profile, including the suppression of specific genes associated with anti-apoptosis including $b c / 2$, and genes for angiogenesis and metastasis. In addition, specific trans-splicing reaction with the targeted hTERT RNA took place in the tumors established as peritoneal carcinomatosis in mice by systemic deliv-
\end{abstract}

ery of the ribozyme. In conclusion, this study demonstrates that an hTERT-specific RNA replacement approach using trans-splicing ribozyme represents a potential modality to treat cancer.

Keywords: gene therapy; microarray analysis; RNA, catalytic; TERT protein, human; trans-splicing

\section{Introduction}

Telomerase is a multicomponent ribonucleoprotein located within the nucleus that synthesizes the repetitive nucleotide sequence forming the telomeres at the end of chromosomes (Morin, 1989). Telomerase activity appears to stabilize telomeres and allow the possibility of cellular immortality (Zhu et al., 1999). Of note, telomerase activity is highly activated in $80-90 \%$ of malignant tissues and immortal cell lines (Kim et al., 1994) and the activity is modulated mainly by the telomerase reverse transcriptase (TERT), the catalytic subunit of the telomerase. Therefore, TERT is a useful target for the development of anti-cancer agent.

The group I ribozyme from Tetrahymena thermophila was previously demonstrated to trans-splice an exon that is attached to its $3^{\prime}$ end onto a separate $5^{\prime}$ exon RNA, not only in vitro (Been and Cech, 1986) but also in E. coli (Sullenger and Cech, 1994) and mammalian cells (Jones et al., 1996). We, as well as other groups, have shown that these group I-based trans-splicing ribozymes can revise mutant transcripts that are associated with several human genetic or malignant diseases (Lan et al., 1998; Phylactou et al., 1998; Watanabe and Sullenger, 2000; Rogers et al., 2002; Shin et al., 2004). Moreover, we demonstrated that transsplicing ribozymes could selectively and specifically induce therapeutic gene activities in specific RNA-expressing cells through specific replacement of the target transcript (Ryu et al., 2003). Accordingly, we developed human TERT (hTERT) RNAreplacing trans-splicing ribozyme that can stimulate the hTERT-dependent cytotoxicity in tumor cells (Kwon et al., 2005). Furthermore, we recently showed that adenoviral vector harboring the ribozyme can either selectively mark tumor cells or selectively induce suicide gene activity in the tumors, thereby regressing the tumors with the 


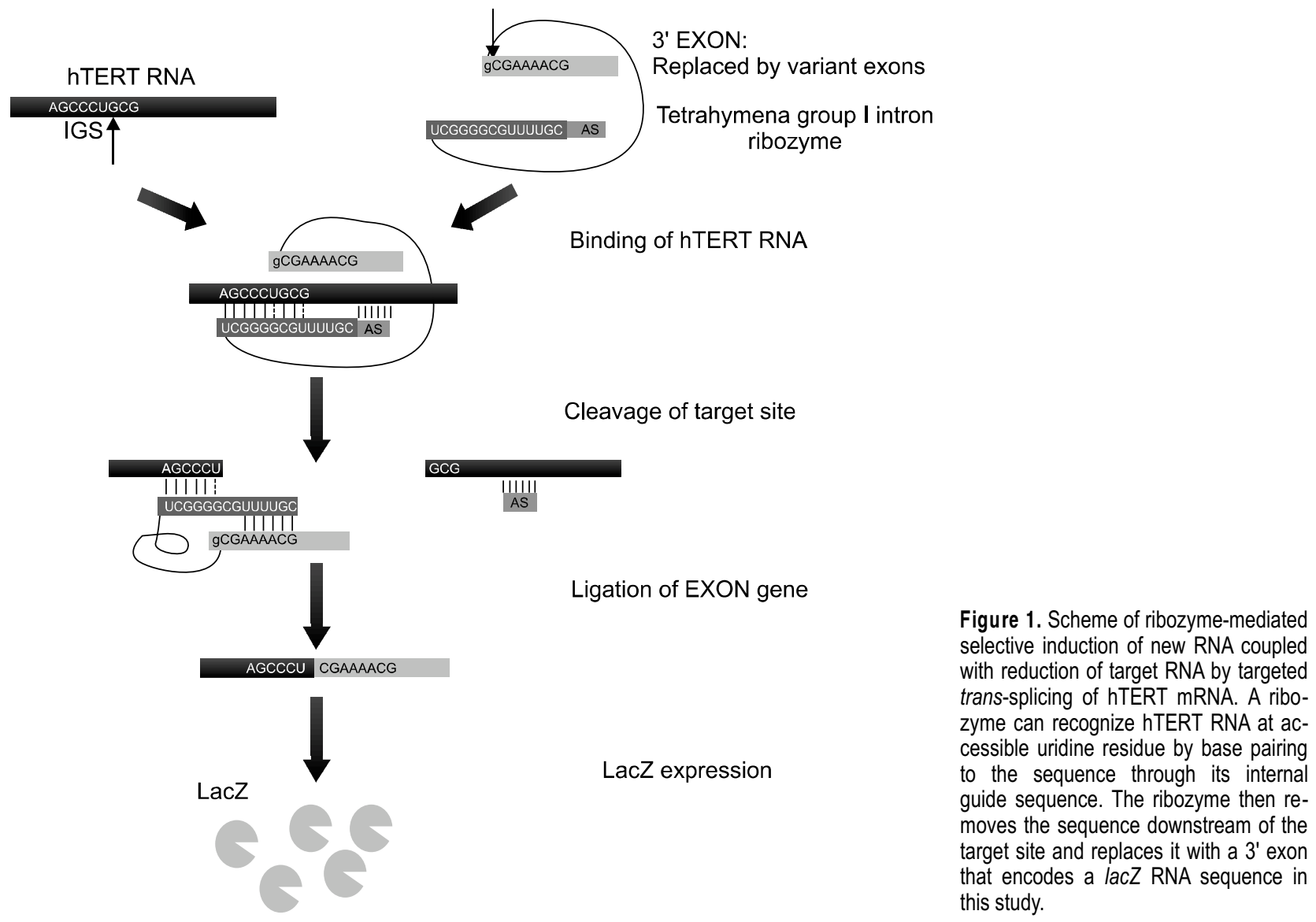

prodrug treatment, in hTERT-expressing tumor xenografts (Hong et al., 2007). These observations indicate that the trans-splicing ribozyme can be used as anti-cancer agents that reprogram cancerspecific transcripts to frustrate the cancerous cells.

The hTERT-specific trans-splicing ribozyme will be more effective as anti-cancer tool because it can induce therapeutic transgene activity selectively in the telomerase-positive cancer cells and can simultaneously reduce the hTERT RNA level in the cells (Figure 1). In this study, to evaluate the dual activity of the ribozyme and to analyze gene expression responses upon hTERT RNA reduction by the ribozyme in vivo, we observed any alterations of the gene expression profiles of tumor nodules in mice with intraperitoneal carcinomatosis after systemic delivery of the hTERT-targeting ribozyme.

\section{Materials and Methods}

\section{Cell lines}

The Hep3B cells (human hepatocellular carcinoma cell line) were purchased from the American Type
Culture Collection. The cells were maintained in Eagle minimal essential medium, supplemented with $10 \%$ heat-inactivated FBS (Join Bio-Innovation, Seoul, Korea), $50 \mathrm{U} / \mathrm{ml}$ penicillin $\mathrm{G}$, and 50 $\mu \mathrm{g} / \mathrm{ml}$ streptomycin (Sigma, St. Louis, MO) at $37^{\circ} \mathrm{C}$ in a humidified atmosphere of $5 \% \mathrm{CO}_{2}$.

\section{Generation of recombinant adenoviral vectors}

We constructed hTERT-specific trans-splicing ribozyme under the control of a phosphoenolpyruvate carboxykinase (PEPCK) promoter as previously described (Song and Lee, 2006). The expression of the specific ribozyme harboring diphtheria toxin A or HSVtk with the PEPCK promoter was shown to be the most effective and specific with regard to the retardation of the growth of $\mathrm{hTERT}^{+}$liver cancer cells, as compared with other liver-specific promoters (Song and Lee, 2006). Recombinant adenovirus vector encoding the PEPCK promoterderived hTERT-targeting ribozyme flanked by the cDNA for LacZ ( $\beta$-galactosidase) as $3^{\prime}$ exon (Figure 2A) was constructed using the in vivo homologous recombination technique in bacteria (BJ5183) with a type 5 adenoviral vector backbone 
A

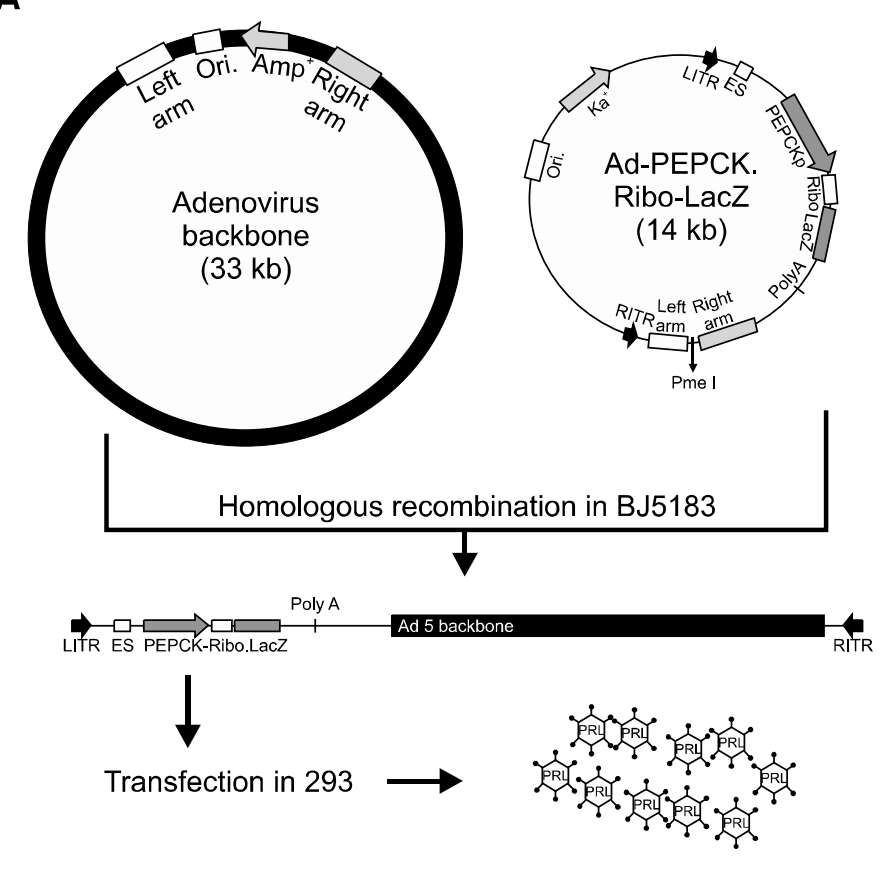

B

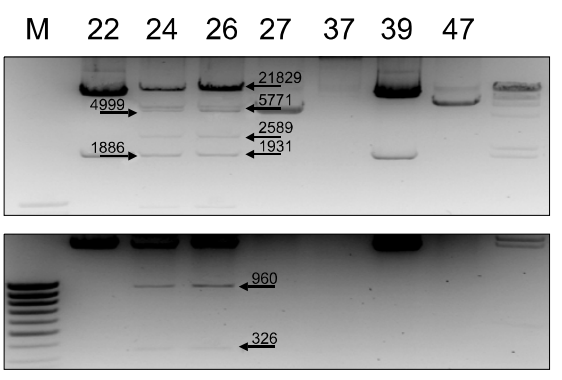

D

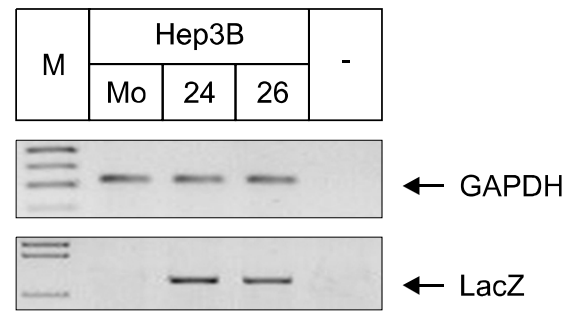

C

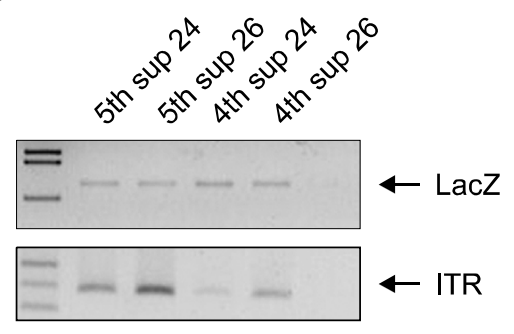

E

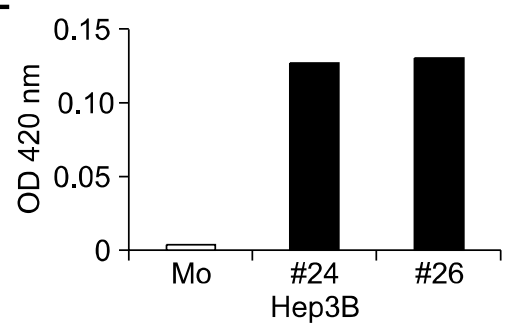

Figure 2. Characterization of recombinant adenovirus encoding the hTERTspecific ribozyme. (A) The PEPCK.RiboLacZ cassette was inserted into the $\mathrm{E} 1$ region of an Adenovirus type 5 backbone by homologous recombination in BJ5183. The resultant vector was transfected into 293 cells, and the recombinant viruses, Ad-PEPCK.Ribo-LacZ, were generated. (B) Each clone of recombinant viral vector generated by homologous recombination in BJ5183 cells was analyzed with Notl. Eight bands of restriction DNA fragments were then shown in the recombinant vectors as indicated with arrows. (C) PCR analysis of lacZ (280 bp) or ITR (210 bp) DNA from clone number 24 or 26 of the recombinant virus genomic DNA generated from $4^{\text {th }}$ or $5^{\text {th }}$ supernatant of the viral infected 293 cells. (D) RT-PCR analysis of GAPDH (210 bp) and lacZ (280 bp) RNA from Hep3B cells infected with clone number 24 or 26 of Ad-PEPCK.Ribo-LacZ. Mo represents mock-infected cells. (E) $\beta$-galactosidase activity of lysates from Hep3B cells infected with each clone of Ad-PEPCK. Ribo-LacZ. in which the $E 1$ and $E 3$ region have been deleted (pAdenoVator $\triangle E 1 / E 3$ backbone E1/E3 deleted Ad5 genome, AdenoVector ${ }^{\mathrm{TM}}$, Qbiogene, Irvine, CA). Briefly, a Spel/BstBI fragment containing the PEPCK promoter-Rib21AS-LacZ sequence was inserted into the pAdenoVator-CMV5-IRES-GFP shuttle vector. To construct recombinant virus vector, the shuttle plasmid was cleaved with Pmel. The linearized fragment was cotransformed into
BJ5183 cells with AdenoVector ${ }^{\mathrm{TM}}$. The recombinant vectors generated by homologous recombination in BJ5183 cells were isolated, analyzed with restriction enzymes, and linearized with Pacl. The linearized vectors were then transfected into 293 cells and the produced recombinant adenoviruses were isolated by three rounds of plaque purification. Recombinant viruses were amplified using 293 cells, purified and concentrated by Vivapure ${ }^{\circledR}$ 
AdenoPACK ${ }^{\mathrm{TM}} 100$ (Sartorius AG, Edgewood, NY). Recombinant adenovirus was titered by determination of the TCID50 (tissue culture infectious dose for $50 \%$ of the cells). We designated the recombinant adenovirus encoding for the ribozyme with lacZ under the control of the PEPCK promoter as Ad-PEPCK.Ribo-LacZ. An adenovirus with lacZ driven by the PEPCK promoter (AdPEPCK-LacZ) was employed as a control. Viral stocks were stored in $10 \%$ sucrose and kept at $-80^{\circ} \mathrm{C}$ until use.

\section{Molecular analysis of recombinant virus}

Recombinant viral vector generated by homologous recombination in BJ5183 cells was confirmed by digestion with Notl. For the analysis of recombinant viral genomic DNA, viral supernatant generated in 293 cells were isolated, and the presence of lacZ and ITR gene was assessed using PCR. Viral supernatant from plaque isolation was infected into Hep3B. Total RNA was then isolated from the cell line and reverse transcribed with an oligo(dT) primer in the presence of $10 \mathrm{mM} \mathrm{L-}$ argininamide to confirm the promoter activity of the recombinant virus. The cDNAs were amplified with lacZ primer (5'-GGAATTCTGGTCGTTTTACAACGTCGTG-3' and 5'-GGGAAGCTTCGGATTGACCGTAATGGGA-3'), or human GAPDH primer (5'TGACATCAAGAAGGTGGTGA-3' and 5'-TGCACGACCCTGTTGCTG-3') as internal control. Infected cells were also used to measure $\beta$-galactosidase activity through incubation of cell extracts in $37^{\circ} \mathrm{C}$ for $2 \mathrm{~h}$ with O-nitrophenyl $\beta$-D-galactopyranoside (Sigma, St. Louis, MO) as a substrate.

\section{Animals}

Four- to 5-week-old male BALB/cAnNCrl nude mice (Orient Bio Inc., Seongnam, Korea) were used throughout this study. The animals were kept under specific pathogen-free (SPF) conditions and acclimated to laboratory conditions for at least $1 \mathrm{wk}$ before use and maintained in Korean FDA animal facility in accordance with AAALAC International Animal Care policy (Accredited Unit-Korea Food and Drug Administration: Unit number-000996).

\section{Intraperitoneal carcinomatosis animal model}

For the peritoneal carcinomatosis model of Hep3B liver cancer cells, $2 \times 10^{7}$ Hep3B cells were intraperitoneally injected into BALB/c male nude mice. In the pilot investigation, the animals showed peritoneal carcinomatosis within 21 days, easily detectable with gross inspection and a binocular stereo- microscope. To analyze specific transgene induction, we injected $1 \times 10^{9}$ pfu Ad-PEPCK-LacZ or Ad-PEPCK.Ribo-LacZ in PBS (total volume, 100 $\mu l)$ intraperitoneally three times with two day interval after the carcinomatosis establishment. Two days after the last virus injection, the established tumor tissues were removed.

\section{RNA analysis}

Following tumor dissection, total RNA was extracted using Tri-Reagent according to the manufacturer's protocol (Molecular Research Center Inc., Cincinnati, OH). After re-suspension in nuclease-free water, the RNA was quantified by UV spectroscopy (Bio-Rad, Hercules, CA), and qualified on a 2100 Bioanalyzer (Agilent, Palo Alto, CA).

To assess the reduction level of the hTERT RNA in vivo by the ribozyme, hTERT cDNA was amplified using real time PCR from $2 \mu \mathrm{g}$ total RNA of the hepatocarcinoma in mice two days after final adenovirus infection into intraperitoneal carcinomatosis mice model. Sequences of primers for the hTERT amplification are 5'-CGGAAGAGTGTCTGGAGCAA-3' and 5'-GGATGAAGCGGAGTCTGGA3'. All reagents except Taq polymerase (Takara, Otsu, Shiga, Japan) were obtained from the SYBRGreen core reagent kit (Molecular Probes, Eugene, OR). The protocol was followed as the manual of the PCR-kit [12.5 $\mu \mathrm{l}$ SYBR Green Mix, $0.2 \mu \mathrm{l}$ cDNA, $1 \mu$ primer pair mix ( $5 \mathrm{pmol} / \mu \mathrm{l}$ each primer), and $11.3 \mu \mathrm{l} \mathrm{H}_{2} \mathrm{O}$ ] (Oh et al., 2006). The conditions for the PCR are at $95^{\circ} \mathrm{C}$ for $30 \mathrm{~s}$, at $55^{\circ} \mathrm{C}$ for $40 \mathrm{~s}$, and at $72^{\circ} \mathrm{C}$ for $1 \mathrm{~min}$ for 40 cycles. The relative kinetic method was applied using a standard curve constructed with 8-fold serial dilutions of hTERT gene obtained from the MCF7 breast cell line which was known to strongly express the hTERT gene (Villa et al., 1998). The standard curve used for PCR is composed of 2 points (equivalent to 1 and $0.125 \mathrm{ng}$ of hTERT PCR product). To control for the expression level of hTERT in the reaction mix, we used human GAPDH. The threshold levels obtained from the hTERT were adjusted to the threshold levels found in the GAPDH reaction to correct for minor variation in cDNA loading. For amplification, we used the Roter-Gene, a real time PCR machine (Corbett Life science, San Francisco, $\mathrm{CA}$ ). To calculate relative quantification values, a threshold cycle $\left(C_{t}\right)$, at which a statistically significant increase in fluorescence occurs, was derived from the resulting PCR profiles of each sample. $C_{t}$ is a measure of the amount of template present in the starting reaction. To correct for different amounts of total cDNA in the starting reaction, $C_{t}$ values for an endogenous control 
(GAPDH) were subtracted from those of the corresponding hTERT level, resulting in $\Delta \mathrm{C}_{\mathrm{t}}$. The relative quantification value of hTERT RNA level is expressed as $2^{-\Delta \mathrm{Ct}}$ giving the relative difference of the ribozyme virus-treated sample compared to the control virus-infected sample.

Level of bc/2 RNA and ribozyme RNA (LacZ) in the adenoviral injected tumor tissues were detected using RT-PCR of total RNA (Du et al., 2006). Primers for the amplification are as follows: bcl2, 5'-CGGAATTCATTGTGGCTGCACTTGCT-3' and 5'-CCCAAGCTTCTGTTGCCCAACTGCAA-3'; LacZ, 5'-GGAATTCATGGTCGTTTTACAACGTCGTG-3' and 5'-GGGAAGCTTCGGATTGACCGTAATGGGA-3'. Production of trans-spliced molecules (TS) with targeted hTERT and the possibility of TS generation with $b c / 2$ RNA were assessed from the viral infected tumors. Total RNA was amplified with primers for TS with the hTERT RNA (5'-GGGGAATTCAGCGCTGCGTCCTGCT-3' and 5'-ATGGTCGTTTTACAACGTCGTGAC-3') or with primers for TS with the bc/2 RNA (5'-CGGAATTCATGTTGTTGGCCGGATCA-3' and 5'-ATGGTCGTTTTACAACGTCGTGAC-3').

\section{Microarray analysis}

We amplified and labeled total RNA from the hepatocarcinoma in mice infected with Ad-PEPCKLacZ or Ad-PEPCK.Ribo-LacZ with Cy3-dCTP or Cy5-dCTP (Perkin Elmer, Boston, MA), respectively. RNA labeling was employed using the Agilent Low Input Linear Amplification kit according to the manufacturer's protocols. Each of Cy3 and Cy5 labeled cDNA $(0.8-1 \mu \mathrm{g})$ was combined and hybridized to 60-mer oligonucleotides microarray with sequences representing 41,194 human genes (Agilent, chip No. HWG251239143090). The slides were hybridized with GlassHyb buffer using the Lucidea SlidePro automated hybridization instrument (Amersham Biosciences, Piscataway, NJ) with the protocol for Agilent slide. The dried slides were then scanned with the GenePix 4000B Microarray Scanner, and the initial images captured by the GenePix Pro 4.1 software (Axon Instruments, Union City, CA). The data were analyzed using Acuity software Version 3.1 (Axon Instruments).

\section{Results}

\section{Construction of recombinant adenovirus}

Expression vector for the hTERT-targeting ribozyme was constructed through the incorporation of a PEPCK.Ribo-LacZ sequence into a type 5 ade- noviral vector backbone (Figure 2A). The resulting plasmid is then linearized and co-transformed into E.coli strain BJ5183 with adenovirus backbone DNA in which the E1 and E3 region have been deleted. Recombinant viral vectors resulting from homologous recombination are selected with kanamycin and screened by restriction enzyme analysis. A restriction digest with Notl gives a restriction pattern as shown in Figure $2 \mathrm{~B}$ (8 bands with size of 21829, 5571, 4999, 2589, 1931, 1886, 960 and $326 \mathrm{bp})$. The recombinants were digested with Pacl and transfected into 293 cells, where the E1 functions can be complemented, by calcium phosphate transfection method to allow production of recombinant adenoviral DNA and packaging into virions. Viral plaques generated in 293 cells were isolated and expanded. After 5 rounds of plaque purification, the expression cassette in the adenoviral vectors was confirmed by PCR of viral genomic DNA and lacZ gene using specific primer (Figure 2C).

Recombinant viruses were amplified using 293 cells, purified and concentrated, and $\beta$-galactosidase assay were performed to examine the expression of the lac $Z 48 \mathrm{~h}$ after infection with either clone number 24 or 26 of recombinant virus into hTERT ${ }^{+}$Hep3B cells. As shown in Figure 2D and $E$, expression of lacZ was detected not only at RNA level but also at protein level in the adenoviral vector-infected Hep3B cells. In contrast, no $\beta$ galactosidase was observed in hTERT $^{-}$SK-LU-1 cells infected with the virus (data not shown). These results demonstrate that the recombinant viral vectors successfully and selectively induce the expression of transgene, lac $Z$, in liver cancer cells.

\section{Microarray analysis of TERT-dependent gene expression}

To determine which transcripts are affected in vivo by the hTERT-targeting trans-splicing ribozyme and to assess the specificity of the ribozyme, we first established animal model with peritoneal carcinomatosis by intraperitoneal transplantation of Hep3B cells into nude mice. Then, we systemically infected adenoviral vector encoding the ribozyme into the mice, and studied the gene expression profile using oligonucleotide microarray experiments in the tumor nodules established in the mice. Changes in the mRNA levels of tumor nodules were analyzed by comparing tumors injected with virus encoding the hTERT-targeting ribozyme (Ad-PEPCK.Ribo-LacZ, PRL) with those that were infected with control virus (Ad-PEPCKLacZ, PL). 
Table 1. Gene expression profile in HCC following injection of peritoneal carcinomatosis mice with Ad-PEPCK.Ribo-LacZ.

\begin{tabular}{|c|c|c|c|c|}
\hline Probe ID & Symbol & Name & Synonyms & d change* \\
\hline \multicolumn{5}{|l|}{ Apoptosis } \\
\hline \multicolumn{5}{|l|}{ Anti-apoptosis } \\
\hline A_23_P42935 & BRAF & $\begin{array}{l}\text { V-raf murine sarcoma viral } \\
\text { oncogene homolog B1 }\end{array}$ & $\begin{array}{l}\text { BRAF1, B-raf 1, B-Raf proto-oncogene } \\
\text { serine/threonine-protein kinase, MGC126806, } \\
\text { MGC138284, p94, RAFB1, v-Raf murine } \\
\text { sarcoma viral oncogene homolog B1 }\end{array}$ & $2.169 \downarrow$ \\
\hline A_24_P192485 & TNFRSF11B & $\begin{array}{l}\text { Tumor necrosis factor receptor } \\
\text { superfamily, member } 11 \mathrm{~b} \\
\text { (osteoprotegerin) }\end{array}$ & $\begin{array}{l}\text { MGC29565, OCIF, OPG, Osteoclastogenesis } \\
\text { inhibitory factor, Osteoprotegerin, TR1, } \\
\text { Tumor necrosis factor receptor superfamily } \\
\text { member 11B precursor }\end{array}$ & $2.392 \downarrow$ \\
\hline A_24_P917766 & BIRC6 & $\begin{array}{l}\text { Baculoviral IAP repeat-containing } \\
6 \text { (apollon) }\end{array}$ & $\begin{array}{l}\text { APOLLON, Baculoviral IAP repeat-containing } \\
\text { protein } 6 \text {, BRUCE, FLJ13726, FLJ13786, } \\
\text { KIAA1289, Ubiquitin-conjugating BIR-domain } \\
\text { enzyme apollon }\end{array}$ & $5.650 \downarrow$ \\
\hline A_23_P115444 & TNFSF18 & $\begin{array}{l}\text { Tumor necrosis factor (ligand) } \\
\text { superfamily, member } 18\end{array}$ & $\begin{array}{l}\text { Activation-inducible TNF-related ligand, AITRL, } \\
\text { GITRL, Glucocorticoid-induced TNF-related } \\
\text { ligand, hGITRL, MGC138237, TL6, Tumor } \\
\text { necrosis factor ligand superfamily member 18, } \\
\text { UNQ149/PRO175 }\end{array}$ & $6.410 \downarrow$ \\
\hline A_24_P512775 & BCL2 & B-cell CLL/lymphoma 2 & Apoptosis regulator $\mathrm{Bcl}-2$ & $8.621 \downarrow$ \\
\hline \multicolumn{5}{|c|}{ Induction of apoptosis } \\
\hline A_23_P218646 & TNFRSF6B & $\begin{array}{l}\text { Tumor necrosis factor receptor } \\
\text { superfamily, member } 6 \mathrm{~b} \text {, decoy }\end{array}$ & $\begin{array}{l}\text { DcR3, DCR3, Decoy receptor 3, Decoy } \\
\text { receptor for Fas ligand, DJ583P15.1.1, M68, } \\
\text { TR6, Tumor necrosis factor receptor superfamily } \\
\text { member 6B precursor, UNQ186/PRO212 }\end{array}$ & $2.596 \uparrow$ \\
\hline A_23_P138635 & BNIP3 & $\begin{array}{l}\text { BCL2/adenovirus E1B } 19 \mathrm{kDa} \\
\text { interacting protein } 3\end{array}$ & $\begin{array}{l}\text { BCL2/adenovirus E1B 19-kDa } \\
\text { protein-interacting protein 3, Nip3, NIP3 }\end{array}$ & $2.469 \uparrow$ \\
\hline A_23_P111343 & BCLAF1 & $\begin{array}{l}\text { BCL2-associated transcription } \\
\text { factor } 1\end{array}$ & $\begin{array}{l}\text { Bcl-2-associated transcription factor 1, } \\
\text { bK211L9.1, Btf, BTF, KIAA0164 }\end{array}$ & $2.162 \uparrow$ \\
\hline A_23_P346311 & BAX & BCL2-associated X protein & $\begin{array}{l}\text { Apoptosis regulator BAX, cytoplasmic } \\
\text { isoform beta, Apoptosis regulator BAX, } \\
\text { membrane isoform alpha, BAX protein, } \\
\text { cytoplasmic isoform delta, BAX protein, } \\
\text { cytoplasmic isoform gamma }\end{array}$ & $2.083 \uparrow$ \\
\hline \multicolumn{5}{|c|}{ Induction of apoptosis resulting from DNA damage response signal transduction } \\
\hline A_23_P60180 & $\mathrm{ABL} 1$ & $\begin{array}{l}\text { V-abl Abelson murine leukemia } \\
\text { viral oncogene homolog } 1\end{array}$ & $\begin{array}{l}\text { Abelson murine leukemia viral oncogene } \\
\text { homolog 1, ABL, c-ABL, JTK7, p150, } \\
\text { Proto-oncogene tyrosine-protein kinase ABL1, } \\
\text { v-abl }\end{array}$ & $2.193 \uparrow$ \\
\hline \multicolumn{5}{|l|}{ Caspase } \\
\hline A_24_P269398 & CASP2 & $\begin{array}{l}\text { Caspase } 2 \text {, apoptosis-related } \\
\text { cysteine peptidase }\end{array}$ & $\begin{array}{l}\text { CASP-2, Caspase-2 precursor, ICH1, ICH-1L, } \\
\mathrm{ICH}-1 \mathrm{~L} / 1 \mathrm{~S}, \mathrm{ICH}-1 \text { protease, NEDD2 }\end{array}$ & $1.996 \uparrow$ \\
\hline A_23_P35906 & CASP4 & $\begin{array}{l}\text { Caspase } 4 \text {, apoptosis-related } \\
\text { cysteine peptidase }\end{array}$ & $\begin{array}{l}\text { CASP-4, Caspase-4 precursor, ICE(rel)II, } \\
\text { ICE(rel)-II, ICEREL-II, ICH2, ICH-2, ICH-2 } \\
\text { protease, Mih1/TX, TX, TX protease }\end{array}$ & $1.733 \uparrow$ \\
\hline A_24_P111342 & CASP9 & $\begin{array}{l}\text { Caspase } 9 \text {, apoptosis-related } \\
\text { cysteine peptidase }\end{array}$ & $\begin{array}{l}\text { APAF3, APAF-3, Apoptotic protease-activating } \\
\text { factor } 3 \text {, Apoptotic protease Mch-6, CASP-9, } \\
\text { CASPASE-9c, Caspase-9 precursor, ICE-LAP6, } \\
\text { ICE-like apoptotic protease } 6, \mathrm{MCH} 6\end{array}$ & $1.705 \uparrow$ \\
\hline
\end{tabular}

*A subset of genes involved in apoptosis, angiogenesis and tumor metastasis, expression of which was increased $(\uparrow)$ or decreased $(\downarrow)$ more than 2-fold by treatment of Ad-PEPCK.Ribo-LacZ when compared with inoculation of the control adenovirus (Ad-PEPCK-LacZ), are shown. In accordance with the real-time PCR data in Figure 3D, level of hTERT mRNA was decreased 6.85 fold by the specific ribozyme. 
Only two days after systemic delivery of the PRL into the intraperitoneal carcinomatosis mice, we observed a $\geq 2$-fold change of RNA level in 1,189 genes including hTERT gene out of surveyed 41,194 human genes in the established human hepatocellular carcinoma (HCC). Some of genes whose expression was changed by PRL are in- volved in apoptosis or tumorigenesis pathway, as shown in the microarray data with siRNA treatment against hTERT or RNA subunit of telomerase, hTER (Li et al., 2005; Shammas et al., 2005) (Table 1). Expression of genes involved in the process of anti-apoptosis was efficiently downregulated by PRL. Specific genes that have been

Table 1. Continued.

\begin{tabular}{|c|c|c|c|c|}
\hline Probe ID & Symbol & Name & Synonyms & ld change* \\
\hline \multicolumn{5}{|l|}{ Angiogenesis } \\
\hline A_24_P167012 & TNFSF15 & $\begin{array}{l}\text { Tumor necrosis factor (ligand) } \\
\text { superfamily, member } 15\end{array}$ & $\begin{array}{l}\text { MGC129934, MGC129935, TL1, TL1A, TNF } \\
\text { ligand-related molecule 1, Tumor necrosis } \\
\text { factor ligand superfamily member } 15 \text {, } \\
\text { Vascular endothelial cell growth inhibitor, } \\
\text { VEGI, VEGI192A }\end{array}$ & $4.032 \downarrow$ \\
\hline A_24_P388810 & APC & Adenomatosis polyposis coli & $\begin{array}{l}\text { Adenomatous polyposis coli protein, DP2, } \\
\text { DP2.5, DP3, FAP, FPC, GS, Protein APC }\end{array}$ & $4.902 \downarrow$ \\
\hline A_24_P402438 & TGFB2 & Transforming growth factor, beta 2 & $\begin{array}{l}\text { BSC-1 cell growth inhibitor, Cetermin, } \\
\text { Glioblastoma-derived T-cell suppressor factor, } \\
\text { G-TSF, MGC116892, Polyergin, TGF-beta2, } \\
\text { TGF-beta-2, Transforming growth factor } \\
\text { beta-2 precursor }\end{array}$ & $5.714 \downarrow$ \\
\hline A_32_P100379 & PDGFRA & $\begin{array}{l}\text { Platelet-derived growth factor } \\
\text { receptor, alpha polypeptide }\end{array}$ & $\begin{array}{l}\text { Alpha platelet-derived growth factor receptor } \\
\text { precursor, CD140a, CD140A, CD140a antigen, } \\
\text { MGC74795, PDGFR2, PDGF-R-alpha }\end{array}$ & $6.250 \downarrow$ \\
\hline A_23_P381992 & ITGAV & $\begin{array}{l}\text { Integrin, alpha V (vitronectin } \\
\text { receptor, alpha polypeptide, } \\
\text { antigen CD51) }\end{array}$ & $\begin{array}{l}\text { CD51, CD51 antigen, Integrin alpha-V } \\
\text { precursor, MSK8, Vitronectin receptor alpha } \\
\text { subunit, VNRA }\end{array}$ & $6.452 \downarrow$ \\
\hline A_23_P428139 & EFNB2 & Ephrin-B2 & $\begin{array}{l}\text { EPH-related receptor tyrosine kinase ligand 5, } \\
\text { Ephrin-B2 precursor, EPLG5, HTKL, Htk-L, } \\
\text { HTK-L, HTK ligand, LERK5, LERK-5, } \\
\text { MGC126226, MGC126227, MGC126228 }\end{array}$ & $6.623 \downarrow$ \\
\hline \multicolumn{5}{|l|}{ Tumor metastasis } \\
\hline A_23_P208126 & SERPINB5 & $\begin{array}{l}\text { Serpin peptidase inhibitor, clade } \\
\text { B (ovalbumin), member } 5\end{array}$ & $\begin{array}{l}\text { Maspin, PI5, Protease inhibitor } 5 \text {, } \\
\text { Serpin B5 precursor }\end{array}$ & $2.155 \downarrow$ \\
\hline A_23_P9513 & MTA1 & Metastasis associated 1 & Metastasis-associated protein MTA1 & $2.278 \downarrow$ \\
\hline A_23_P94800 & S100A4 & $\begin{array}{l}\text { S100 calcium binding protein } \\
\text { A4 (calcium protein, calvasculin, } \\
\text { metastasin, murine placental } \\
\text { homolog) }\end{array}$ & $\begin{array}{l}\text { 18A2, 42A, Calvasculin, CAPL, Metastasin, } \\
\text { MTS1, Mts1 protein, P9KA, PEL98, Placental } \\
\text { calcium-binding protein, Protein S100-A4, } \\
\text { S100 calcium-binding protein A4 }\end{array}$ & $2.392 \downarrow$ \\
\hline A_24_P33140 & TIMP3 & $\begin{array}{l}\text { TIMP metallopeptidase inhibitor } 3 \\
\text { (Sorsby fundus dystrophy, } \\
\text { pseudoinflammatory) }\end{array}$ & $\begin{array}{l}\text { HSMRK222, K222, K222TA2, Metalloproteinase } \\
\text { inhibitor } 3 \text { precursor, MIG-5 protein, SFD, } \\
\text { TIMP-3, Tissue inhibitor of metalloproteinases- } 3\end{array}$ & $2.994 \downarrow$ \\
\hline A_24_P929003 & ITGB3 & $\begin{array}{l}\text { Integrin, beta } 3 \text { (platelet } \\
\text { glycoprotein IIla, antigen CD61) }\end{array}$ & $\begin{array}{l}\text { CD61, CD61 antigen, GP3A, GPIIla, Integrin } \\
\text { beta-3 precursor, Platelet membrane } \\
\text { glycoprotein IIla }\end{array}$ & $4.237 \downarrow$ \\
\hline A_24_P388810 & APC & Adenomatosis polyposis coli & $\begin{array}{l}\text { Adenomatous polyposis coli protein, DP2, } \\
\text { DP2.5, DP3, FAP, FPC, GS, Protein APC }\end{array}$ & $4.902 \downarrow$ \\
\hline A_23_P71073 & TWIST1 & $\begin{array}{l}\text { Twist homolog } 1 \\
\text { (acrocephalosyndactyly } 3 ; \\
\text { Saethre-Chotzen syndrome) } \\
\text { (Drosophila) }\end{array}$ & $\begin{array}{l}\text { ACS3, BPES2, BPES3, H-twist, SCS, TWIST, } \\
\text { Twist-related protein } 1\end{array}$ & $7.813 \downarrow$ \\
\hline
\end{tabular}


found to play important roles in angiogenesis or metastasis were also down-regulated. Some of genes which were up-regulated were participated in apoptosis induction process. In contrast, no significant alteration in the expression level of genes involved in immune response including cytokines, interferons, or interferon-stimulated genes was observed by PRL injection, suggesting that ribozyme expression via $\mathrm{PRL}$ treatment of mice did not induce dsRNA-mediated nonspecific interferon response in the established $\mathrm{HCC}$.

\section{Effects on hTERT RNA level by Ad-PEPCK.Ribo-LacZ}

To verify the results obtained from the microarray experiments, we assessed RNA level of hTERT genes by real time quantitative PCR using the SYBR Green method (Figure 3A). Expression level of the housekeeping gene, GAPDH, showed only minor difference between PL- or PRL-infected tumor groups and served as both a control for RT-PCR performance and a reference for relative quantification (Figure 3B). The analytical sensitivity of the real-time RT-PCR was determined with a series of dilutions of RT-PCR product ( 1 and 0.125 ng) of hTERT RNA. Amplification of the hTERT RNA transcripts at different concentrations showed linearity, and $\mathrm{R}^{2}$ was 0.99 (Figure $3 \mathrm{C}$ ). The threshold cycle number (Ct) of PCR of the hTERT RNA in tumors infected with PRL $(C t=15.1)$ was higher than that with $\mathrm{PL}(\mathrm{Ct}=12.8)$ (Figure $\mathrm{D})$. These results strongly suggest that the level of hTERT RNA was more than 4 fold reduced in tumors by the adenovirus encoding the hTERTspecific ribozyme, compared with the control virus.
A

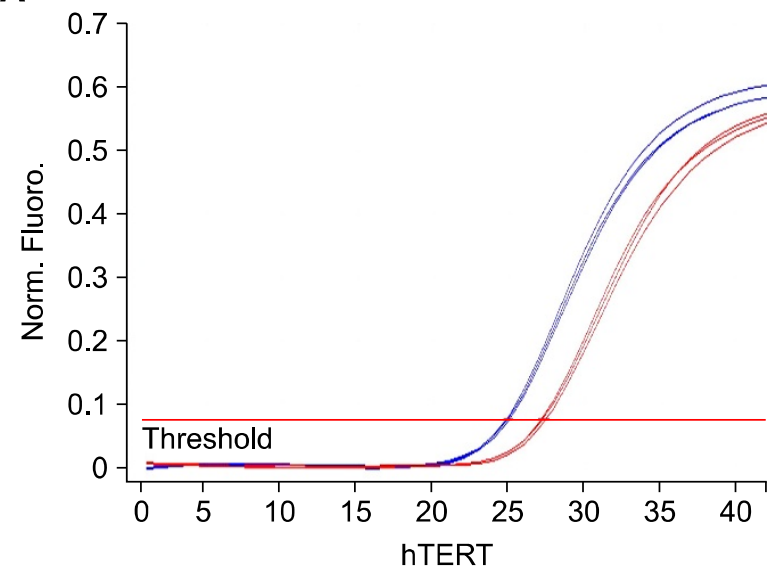

C

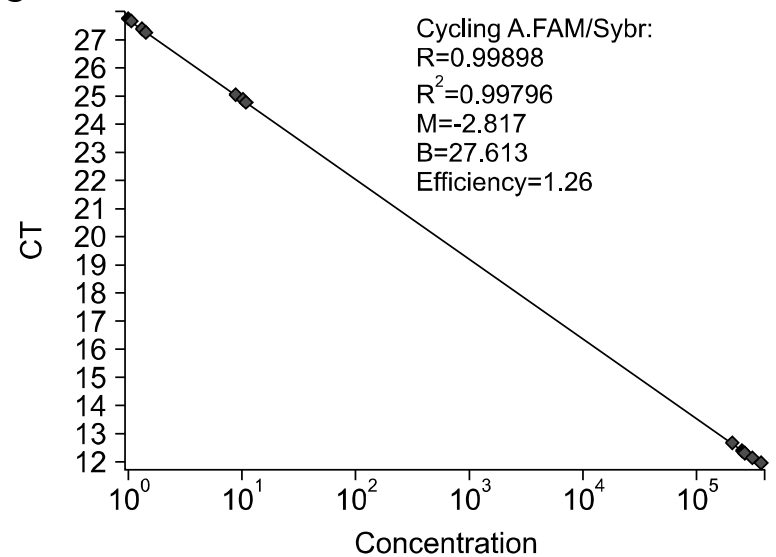

B

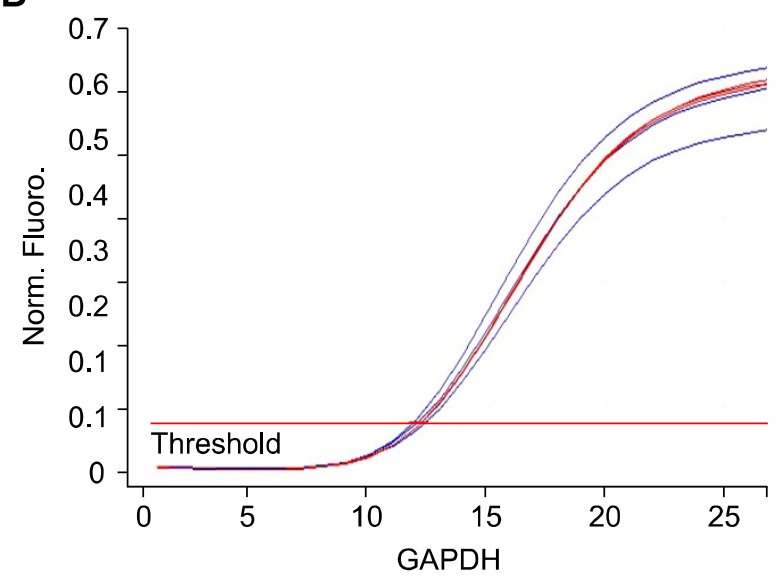

D

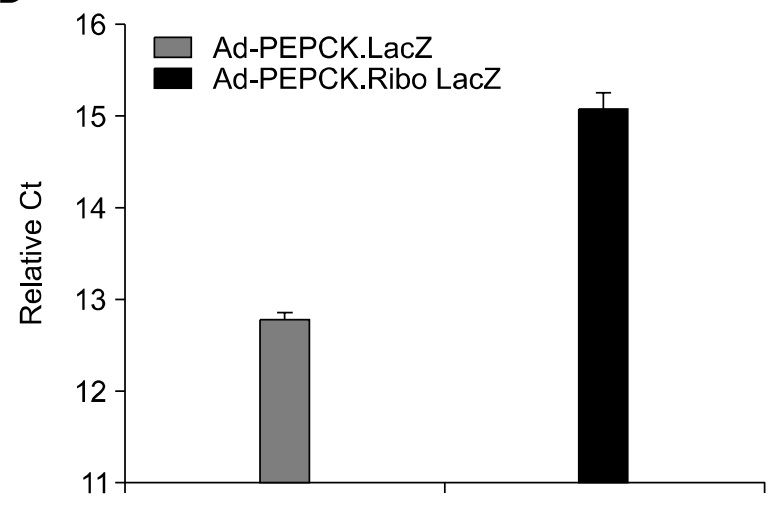

Figure 3. Real-time PCR analysis of hTERT (A) and GAPDH (B) mRNA amounts in tumor nodules infected by Ad-PEPCK-LacZ (blue line) or Ad-PEPCK.Ribo-LacZ (red line): (C) Linear plot of Ct in each sample was plotted against concentration of standard hTERT CDNA. $R^{2}=0.99$ (D) The threshold cycle $\left(C_{t}\right)$ of $h T E R T$ RNA in each viral infected tumor was normalized against $C_{t}$ of GAPDH RNA in the corresponding sample. 
A

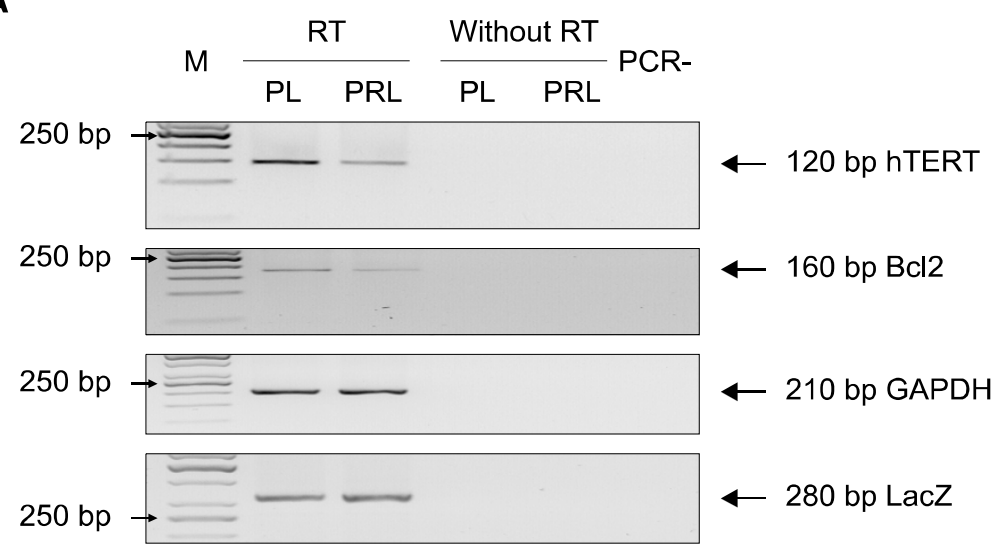

B

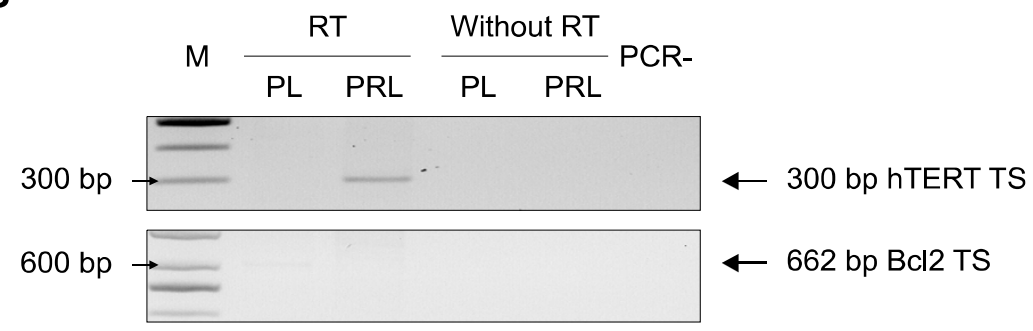

Figure 4. RNA expression patterns in tumor tissues of mice with peritoneal carcinomatosis after injection of Ad-PEPCK-LacZ (PL) or Ad-PEPCK.Ribo-LacZ (PRL). (A) Level of hTERT, bc/2, and ribozyme RNA (LacZ) were detected using RT-PCR of total RNA in the adenovirally injected tumor tissues. As an internal control, the $210 \mathrm{bp}$ amplified RNA product of human GAPDH is presented for each sample. (B) Production of trans-spliced molecules (TS) with targeted hTERT and the possibility of TS generation with $b c / 2$ RNA were assessed from the viral infected tumors.

\section{Analysis of gene expression affected by Ad-PEPCK.Ribo-LacZ}

Using RT-PCR analysis, we confirmed PRL-mediated downregulation of the $b c / 2$ gene expression, which was found to decrease more than 8 fold from the microarrray analysis (Figure 4A). In contrast with generation of trans-splicing product with the targeted hTERT RNA by PRL, no transsplicing was created with $b c / 2$ RNA, indicating that at least the reduction of $b c / 2$ gene expression was not due to nonspecific trans-splicing reaction with the hTERT-targeting ribozyme (Figure 4B). Moreover, RACE RT-PCR and sequencing analysis revealed that all of the trans-splicing products generated in HCC of the PRL-injected mice were from reactions only with the targeted hTERT RNA, implying target specificity of the trans-splicing ribozyme in vivo (data not shown). Collectively with the microarray analysis, these results indicated that PEPCK promoter-driven trans-splicing ribozyme specifically replaced the hTERT RNA and efficiently reduced RNA level of the target in vivo, resulting in alteration in the global gene expression pattern indicative of novel response pathway such as induction of apoptosis and suppression of angiogenesis or metastasis.

\section{Discussion}

The aim of this study was to validate in vivo function of hTERT-targeting trans-splicing ribozymes with molecular analysis of affected gene expression. The hTERT-specific trans-splicing ribozyme will be more advantageous than other anti-cancer agents because the ribozyme could selectively induce targeted expression of the therapeutic gene product in hTERT ${ }^{+}$cancer cells and simultaneously decrease in the level of target hTERT transcript, hence reducing endogenous telomerase activity. To broadly screen for molecular effects by the hTERT-specific ribozyme, we performed oligonucleotide microarray analysis of peritoneal carcinomatosis infected with the ribozyme-encoding adenovirus using the Whole Human Genome Oligo Microarray Kit from agilent, which represent all known genes and transcripts in the human genome. As expected, the level of hTERT RNA in tumors was significantly reduced by systemic delivery of PRL encoding the specific ribozyme. Moreover, approximately $3 \%$ of the whole human genes were changed in their expression level in tumors infected with PRL, compared with tumors with PL. No significant difference in the $\beta$-galactosidase activity was observed between tumors infected with PL and PRL (data not shown). Thus, this alteration might not be due to LacZ expression 


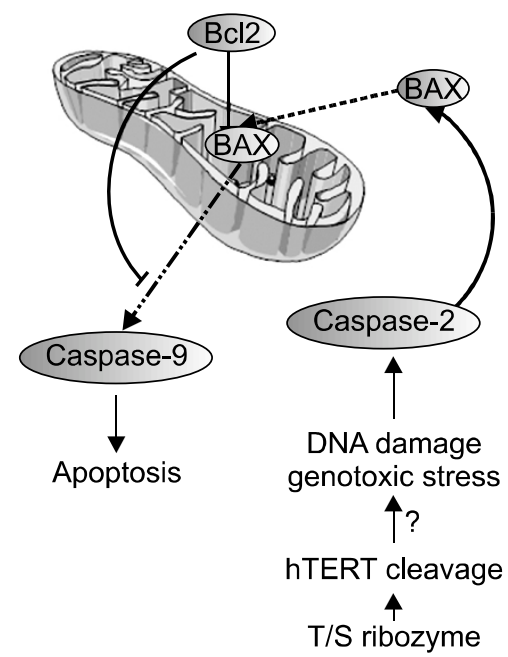

Figure 5. Scheme of potential pathway to induce mitochondrial apoptosis through hTERT reduction mediated by trans-splicing (T/S) ribozyme.

induced by the ribozyme but due to the inhibition of the hTERT RNA level.

Gross changes were observed two days after the adenovirus infection in the expressional levels of various genes involved in apoptosis and tumorigenesis, which may in part explain other findings that human cancer cells have a rapid and defined growth inhibitory response to telomerase depletion, even without telomere shortening (Folini et al., 2003; Li et al., 2004, 2005). It is remarkable that the vast majority of apoptosis regulators which were down-regulated in ribozyme-expressing tumor nodules are proapoptotic genes. At this point, it is difficult to draw conclusions how hTERT may interact within the apoptotic cascade. However, the result of this experiment indicated the kinds of dysregulated genes, and therefore, could further guide our research direction regarding TERT function. The apoptosis regulating function of hTERT will be complicated, as suggested by a recent study describing the role of telomerase on apoptosis through modulation of $\mathrm{Bcl} 2$ expression (Del Buffalo et al., 2005). In this study, we observed in vivo molecular associations between the level of hTERT mRNA and $b c / 2$ transcript, which resulted from systemic delivery of the hTERT-specific transsplicing ribozyme (Figure 5), in agreement with the observation by Del Bufalo et al. (2005), who showed that the inhibition of telomerase expression induced mitochondrial apoptosis by targeted intervention in $\mathrm{Bcl} 2$ expression and function. hTERT overexpression was also shown to interfere at an early stage of cell death pathway involved in mitochondrial alterations (Massard et al., 2006). Moreover, telomerase was recently demonstrated to not only stabilize telomeres but also activate the expression of proliferation enhanced genes (Smith et al., 2003). Furthermore, nuclear-targeted hTERT showed enhanced antiapoptotic activity by inhibition of nuclear export of endogenous hTERT in human embryonic kidney cells (Haendeler et al., 2003). These results together with our gene expression profile data suggest that hTERT may directly or indirectly modulates the expression of genes implicated in intrinsic apoptosis pathway controlled by $b c / 2$.

In conclusion, this study points to in vivo function of the hTERT-specific trans-splicing ribozyme. The ribozyme efficiently reduced the hTERT RNA level, which in turn reduced gene expression involved in anti-apoptosis, angiogenesis and tumor metastasis. The observation of the relation of apoptosis, angiogenesis and tumor metastasis with the activity and/or expression level of telomerase will be positively influential to design telomerase- targeting agent as anti-cancer modality because the level of these pathways noticeably affects tumor growth. Moreover, at the same time with global change of gene expression, the hTERT- specific ribozyme induced target-dependent generation of trans-splicing RNA product in vivo. Therefore, present study proves potential usefulness of the RNA replacement strategy with hTERT- specific trans-splicing ribozyme as therapeutic approach to cancer.

\section{Acknowledgements}

This work was supported by the Korea Science and Engineering Foundation (M10534000004-06N3400-00410). M.S. Song is a recipient of Brain Korea 21 fellowship.

\section{References}

Been MD, Cech TR. One binding site determines sequence specificity of Tetrahymena pre-rRNA self-splicing, transsplicing, and RNA enzyme activity. Cell 1986;47:207-16

Del Bufalo D, Rizzo A, Trisciuoglio D, Cardinali G, Torrisi MR, Zangemeister-Wittke U, Zupi G, Biroccio A. Involvement of hTERT in apoptosis induced by interference with $\mathrm{Bcl}-2$ expression and function. Cell Death Differ 2005;12:1429-38

Du ZX, Zhang HY, Gao DX, Wang HQ, Li YJ, Liu GL. Antisurvivin oligonucleotides inhibit growth and induce apoptosis in human meduallary thyroid carcinoma cells. Exp Mol Med 2006;38:230-40

Folini M, Berg K, Millo E, Villa R, Prasmickaite L, Daidone MG, Benatti U, Zaffaroni N. Photochemical internalization of a peptide nucleic acid targeting the catalytic subunit of human telomerase. Cancer Res 2003;63:3490-4

Haendeler J, Hoffmann J, Brandes RP, Zeiher AM, Dimmeler 
S. Hydrogen peroxide triggers nuclear export of telomerase reverse transcriptase via Src kinase family-dependent phosphorylation of tyrosine 707. Mol Cell Biol 2003;23:4598610

Hong SH, Jeong JS, Lee YJ, Jung HI, Cho KS, Kim CM, Kwon $\mathrm{BS}$, Sullenger BA, Lee SW, Kim IH. In vivo reprogramming of hTERT by trans-splicing ribozyme to target tumor cells. Mol Ther 2007; Epub ahead of print

Jones JT, Lee SW, Sullenger BA. Tagging ribozyme reaction sites to follow trans-splicing in mammalian cells. Nat Med 1996;2:643-8

Kim NW, Piatyszek MA, Prowse KR, Harley CB, West MD, Ho PL, Coviello GM, Wright WE, Weinrich SL, Shay JW. Specific association of human telomerase activity with immortal cells and cancer. Science 1994;266:2011-5

Kwon BS, Jung HS, Song MS, Cho KS, Kim SC, Kimm K, Jeong JS, Kim IH, Lee SW. Specific regression of human cancer cells by ribozyme-mediated targeted replacement of tumor-specific transcript. Mol Ther 2005;12:824-34

Lan N, Howrey RP, Lee SW, Smith CA, Sullenger BA. Ribozyme-mediated repair of sickle $\beta$-globin mRNAs in erythrocyte precursors. Science 1998;280:1593-6

Li S, Rosenberg JE, Donjacour AA, Botchkina IL, Hom YK, Cunha GR, Blackburn EH. Rapid inhibition of cancer cell growth induced by lentiviral delivery and expression of mutant-template telomerase RNA and anti-telomerase short-interfering RNA. Cancer Res 2004;64:4833-40

Li S, Crothers J, Haqq CM, Blackburn EH. Cellular and gene expression responses involved in the rapid growth inhibition of human cancer cells by RNA interference-mediated depletion of telomerase RNA. J Biol Chem 2005;280: 23709-17

Massard C, Zermati Y, Pauleau AL, Larochette N, Métivier D, Sabatier L, Kroemer G, Soria JC. hTERT: a novel endogenous inhibitor of the mitochondrial cell death pathway. Oncogene 2006;25:4505-14

Morin GB. The human telomere terminal transferase enzyme is a ribonucleoprotein that synthesizes TTAGGG repeats. Cell 1989;59:521-9

Oh DY, Jung KH, Yang BH, Lee JS, Choi IG, Chai YG. Naltrexone influences protein kinase $\mathrm{C} \varepsilon$ and integrin $\alpha 7$ activity in SH-SY5Y neuroblastoma cells. Exp Mol Med 2006;38:100-6

Phylactou LA, Darrah C, Wood MJ. Ribozyme-mediated trans-splicing of a trinucleotide repeat. Nat Genet 1998; 18:378-81

Rogers CS, Vanoye CG, Sullenger BA, George AL Jr. Functional repair of a mutant chloride channel using a trans-splicing ribozyme. J Clin Invest 2002;110:1783-9

Ryu KJ, Kim JH, Lee SW. Ribozyme-mediated selective induction of new gene activity in hepatitis $C$ virus internal ribosome entry site-expressing cells by targeted transsplicing. Mol Ther 2003;7:386-95

Shammas M, Koley H, Batche R, Bertheau RC, Protopopov A, Munshi NC, Goyal RK. Telomerase inhibition by siRNA causes senescence and apoptosis in Barrett's adenocarcinomas cells: mechanism and therapeutic potential. Mol Cancer 2005;4:24

Shin KS, Sullenger BA, Lee SW. Ribozyme-mediated induction of apoptosis in human cancer cells by targeted repair of mutant p53 RNA. Mol Ther 2004;10:365-72

Smith LL, Coller HA, Roberts JM. Telomerase modulates expression of growth-controlling genes and enhances cell proliferation. Nat Cell Biol 2003;5:474-9

Song MS, Lee SW. Cancer-selective induction of cytotoxicity by tissue-specific expression of targeted trans-splicing ribozyme. FEBS Lett 2006;580:5033-43

Sullenger BA, Cech TR. Ribozyme-mediated repair of defective mRNA by targeted, trans-splicing. Nature 1994;371: 619-22

Villa R, Zaffaroni N, Folini M, Martelli G, De Palo G, Daidone MG, Silvestrini R. Telomerase activity in benign and malignant breast lesions: a pilot prospective study on fine-needle aspirates. J Natl Cancer Inst 1998;90:537-9

Watanabe T, Sullenger BA. RNA repair: a novel approach to gene therapy. Adv Drug Deliv Rev 2000;44:109-18

Zhu J, Wang H, Bishop JM, Blackburn EH. Telomerase extends the lifespan of virus-transformed human cells without net telomere lengthening. Proc Natl Acad Sci USA 1999;96:3723-8 